\title{
Characterisation and Modelling of Barium Titanate-Silver Composites
}

\author{
S. PANTENY, R. STEVENS, and C. R. BOWEN \\ Materials Research Centre, Department of Engineering and Applied Science, \\ University of Bath, Bath, BA2 7AY, UK
}

(Received August 8, 2003; in final form January 5, 2004)

Barium titanate-silver particulate composites were prepared by attrition milling $\mathrm{BaTiO}_{3}$ and silver nitrate, followed by conventional processing. After manufacture, microstructural, mechanical and electrical characterisation was undertaken to examine the influence of silver addition on properties. The effect of the addition of conductive inclusions in a capacitive matrix on properties, such as permittivity, was simulated using a random network of resistors and capacitors. Model results were compared with experimental results.

Keywords: Silver; barium titanate; composite; modelling

\section{INTRODUCTION}

Recently, nano-sized particles such as silicon carbide have been used to enhance the mechanical properties of structural ceramics, such as alumina [1] and electroceramics, such as barium titanate [2]. Previous research on the barium titanate-silicon carbide system indicates that semi-conducting reaction phases are formed which suggests that any benefits in mechanical properties are at the expense of electrical properties [3]. Improvements in specific properties, such as mechanical strength and toughness, have been observed by other researchers on addition of conductive particles into electroceramics [4]. In this work, silver particles have been added to barium titanate. Due to limited solid-solubility of silver in barium titanate, no significant solid-solutions or reaction phases are expected to form. The changes in microstructure and the modifications to mechanical and electrical properties are examined. Modelling of dielectric properties by the random incorporation of resistive defects in a dielectric is studied using a random resistor-capacitor (R-C) network. 


\section{EXPERIMENTAL}

Barium titanate (Morgan Electroceramics, 1-2 $\mu \mathrm{m}$ ) and silver nitrate crystals (Aldrich, 20, 913-9) were attrition milled with ethanol. The slurry was dried and sieved $\left(150 \mu \mathrm{m}\right.$ mesh). After calcination at $300^{\circ} \mathrm{C} / 2 \mathrm{hrs}$ to decompose the silver nitrate, green compacts were formed by cold isostatic pressing at $150 \mathrm{MPa}$ and then sintered at $1300^{\circ} \mathrm{C} / 2 \mathrm{hrs}$. Electroded samples were corona poled using a temperature of $130^{\circ} \mathrm{C}$ and a potential $>7.5 \mathrm{kV}$ with a tip height of $2 \mathrm{~cm}$.

\section{EXPERIMENTAL RESULTS}

The complete decomposition of silver nitrate to silver during sintering and the lack of additional reaction phases were both confirmed by x-ray diffraction analysis of the sintered composites. The final sintered density reduced with silver addition from the monolithic value of $95 \%$ to $86 \%$ with $13 \mathrm{wt} \%$ silver. Analysis of the microstructure (Fig. 1a) showed large silver particles $(>1 \mu \mathrm{m})$ situated at grain boundaries, while spherical particles $<1 \mu \mathrm{m}$ tended to reside within the grains. Figure $1 \mathrm{~b}$ is a transmission electron micrograph of a $100 \mathrm{~nm}$ silver particle within a grain, showing no reaction phases and a dislocation network around the particle, possibly formed as a result of thermal stresses.

In terms of mechanical properties, pure barium titanate had a sintered strength and fracture toughness of $100 \mathrm{MPa}$ and $\sim 2 \mathrm{MPa} . \mathrm{m}^{0.5}$ respectively. Incorporation of silver (18 wt \%) increased the strength to $120 \mathrm{MPa}$ with no significant change in fracture toughness. Figure 2 a shows that the $d_{33}$ and $d_{31}$ piezoelectric coefficients gradually decreased with silver content.
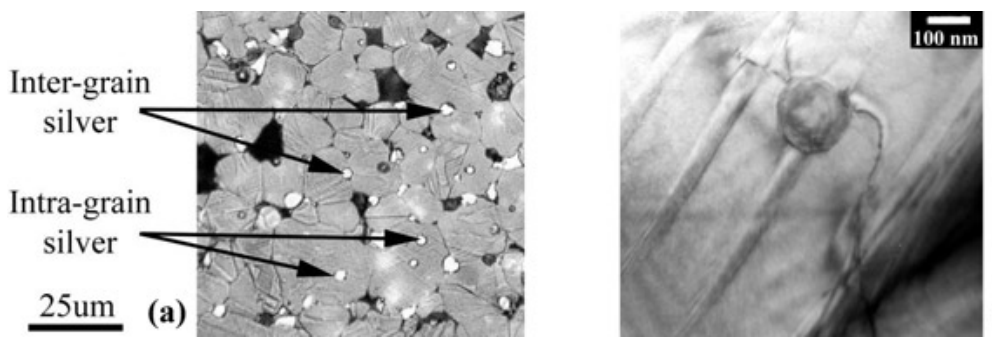

(b)

FIGURE 1 (a) Microstructure of composite showing inter and intra granular particles and (b) TEM of $\mathrm{Ag}$ particle in a $\mathrm{BaTiO}_{3}$ matrix. 

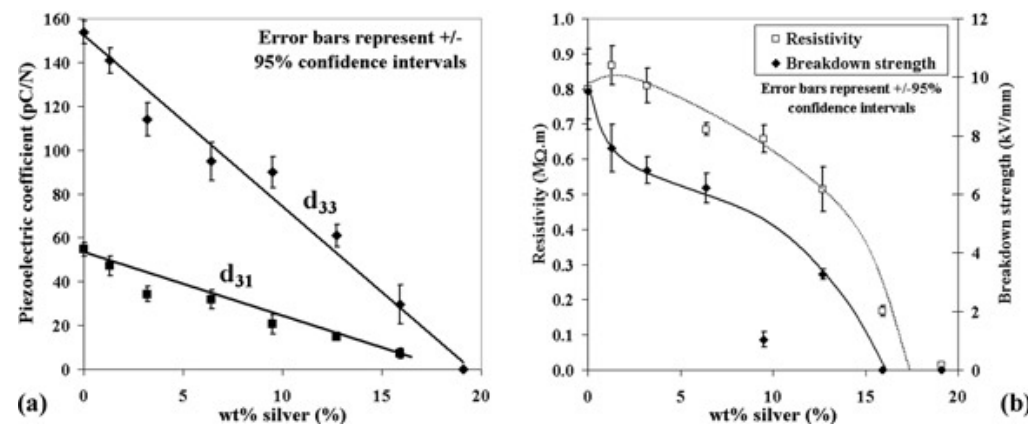

FIGURE 2 Graphs showing (a) gradual decrease in piezoelectric coefficients, $d_{33}$ and $\mathrm{d}_{31}$ and (b) a strong decrease in resistivity and dielectric breakdown strength as a function of silver particle content.

Addition of silver reduces the resistivity and dielectric strength (Fig. 2b), particularly at high silver contents where percolation begins. The increase in conductivity with silver content may reduce the electric field influencing domains during poling and contribute towards the reduction in piezoelectric coefficient. The relative permittivity of monolithic barium titanate was 1500 , comparable to the literature [5]. At low silver contents the benefits to the relative permittivity were small, however, with $10 \mathrm{wt} \%$ silver a significant increase to $\sim 4800$ was observed (Fig. 3a). This increase could be due to the silver particles acting as inter-electrodes within the barium titanate and
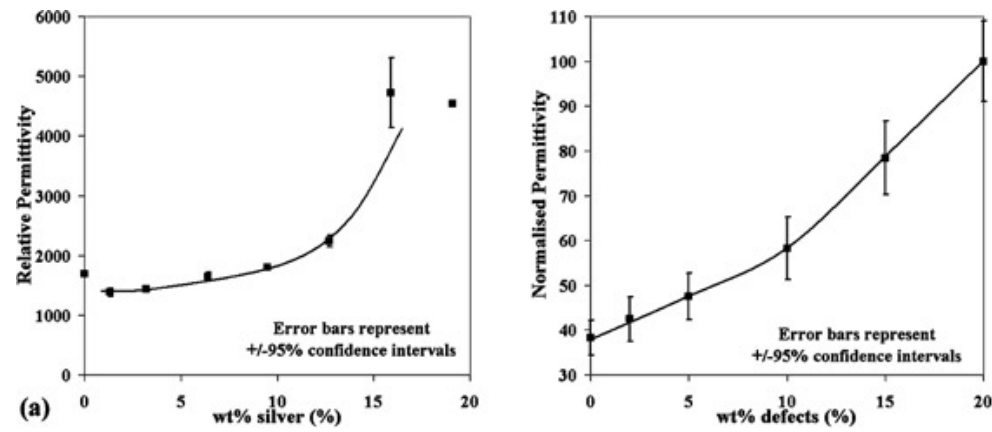

(b)

FIGURE 3 Graphs showing (a) increasing permittivity with silver particle content (measured at $1 \mathrm{kHz}$ ) and (b) permittivity of a reference $30 \%$ resistor-70\% capacitor random network with random components replaced with $1 \mu \Omega$ resistors to simulate conductive defects (Average of 256 simulations at $1 \mathrm{kHz}$ with a 3D matrix of 16 component side length). 
increasing the local electric field [4]. Additional electrical characterisation (polarisation-field) was conducted and will be reported elsewhere.

\section{MODELLING}

Recent research has shown that the dielectric response of a solid can be represented by a large random array of resistors and capacitors [6]. A reference three dimensional network of $70 \%$ capacitors $(1 \mathrm{pF})-30 \%$ resistors $(1 \mathrm{k} \Omega)$ was generated to simulate the dielectric response of the matrix. The network components were randomly replaced with low resistance $(1 \mu \Omega)$ defects in order to represent the addition of a conductive phase. Figure $3 \mathrm{~b}$ is a graph of the permittivity of the network at a fixed frequency as a function of conductive particle content. As observed practically, both the magnitude and variation of permittivity increase with increasing defect content.

\section{CONCLUSIONS}

The addition of silver to barium titanate produces a composite that has potentially improved mechanical and electrical properties. Although improvement in properties such as strength and permittivity are observed, there is also a decrease in dielectric strength that limits the maximum electric field the materials can withstand. Dielectric modelling using a random resistor-capacitor network with the addition of low resistive components indicated a similar permittivity trend to that observed experimentally, providing an insight into the mechanism by which permittivity increased with conductive particle addition.

\section{REFERENCES}

[1] R. Todd, Alumina/SiC nanocomposites-Big things from small packages. In 21 st Century Ceramics, edited by D. P. Thompson and H. Mandal (Cambridge, The University Press, 1996), 225-248.

[2] H. J. Hwang and K. Niihara, "Perovskite-type $\mathrm{BaTiO}_{3}$ ceramics containing particulate SiC: Part II-Microstructure and mechanical properties," J. Mat. Sci. 33, 549-558 (1998).

[3] S. Panteny, C. Bowen, and R. Stevens, "Piezoelectric particulate reinforced nanocomposites," In Ferroelectrics 2000 UK, edited by M. Alford and E. Yeatman (Oxford: The Alden Group, 2000), 75.

[4] R. Chen, X. Wang, Z. Gui, and L. Li, "Effect of silver addition on the dielectric properties of barium titanate-based X7R ceramics,” J. Am. Ceram. Soc. 86, 1022-1024 (2003). 
[5] G. Arlt, D. Hennings, and De G. With, "Dielectric properties of fine-grained barium titanate ceramics, American Inst. of Phys.” J. Appl. Phys., 58(4), 1619-1625 (15 Aug 1985).

[6] D. Almond and B. Vaines, "The dielectric properties of random R-C networks as an explanation of the 'universal' power law dielectric response of solids," J. Phys. Condens Mat. 11, 9081-9093 (1999). 